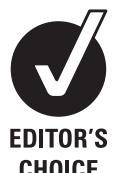

CHOICE

${ }^{1}$ Section of Cognitive

Neuropsychiatry, Department of Psychological Medicine, Institute of Psychiatry, London, UK

${ }^{2}$ Department of Clinical Neurosciences, Western General Hospital, Edinburgh, UK ${ }^{3}$ Department of Psychological Medicine, Institute of Psychiatry, King's College London, Weston Education Centre, London, UK

\section{Correspondence to}

Dr R A A Kanaan, Department of Psychological Medicine, Institute of Psychiatry, King's College London, Weston Education Centre, London SE5 9RJ, UK:

Richard.Kanaan@kcl.ac.uk

Received 20 November 2009 Revised 5 March 2010 Accepted 15 April 2010 Published Online First 29 October 2010

\title{
Conversion disorder: a problematic diagnosis
}

\author{
Timothy R J Nicholson, ${ }^{1}$ Jon Stone, ${ }^{2}$ Richard A A Kanaan ${ }^{3}$
}

\section{ABSTRACT}

The diagnosis of conversion disorder is problematic. Since doctors have conceptually and practically differentiated the symptoms from neurological ('organic') disease it has been presumed to be a psychological disorder, but the psychological mechanism, and how this differs from feigning (conscious simulation), has remained elusive. Although misdiagnosis of neurological disease as conversion disorder is uncommon, it remains a concern for clinicians, particularly for psychiatrists who may be unaware of the positive ways in which neurologists can exclude organic disease. The diagnosis is anomalous in psychiatry in that current diagnostic systems require that feigning is excluded and that the symptoms can be explained psychologically. In practice, feigning is very difficult to either disprove or prove, and a psychological explanation cannot always be found. Studies of childhood and adult psychological precipitants have tended to support the relevance of stressful life events prior to symptom onset at the group level but they are not found in a substantial proportion of cases. These problems highlight serious theoretical and practical issues not just for the current diagnostic systems but for the concept of the disorder itself. Psychology, physiology and functional imaging techniques have been used in attempts to elucidate the neurobiology of conversion disorder and to differentiate it from feigning, but while intriguing results are emerging they can only be considered preliminary. Such work looks to a future that could refine our understanding of the disorder. However, until that time, the formal diagnostic requirement for associated psychological stressors and the exclusion of feigning are of limited clinical value. Simplified criteria are suggested which will also encourage cooperation between neurology and psychiatry in the management of these patients.

\section{INTRODUCTION}

Conversion disorder is primarily defined by neurological symptoms such as weakness, sensory loss or blackout which, due to internal inconsistency or incongruity with known patterns of disease, are not thought to be caused by a neurological disorder. Patients with these symptoms, variously known as functional, non-organic, hysterical, psychogenic or dissociative symptoms, are as common in neurology settings as multiple sclerosis or Parkinson's disease ${ }^{1}$ and have poor outcomes. ${ }^{2}{ }^{3}$ Despite their clinical importance there has been only marginal progress in our understanding of this condition relative to many other neurological and psychiatric disorders.

If the neurological symptoms in conversion disorder are not due to neurological disease then what are they due to? For the past century psychological models have predominated, explaining the symptoms as the result of subconscious processes. Others, however, have thought that feigning (conscious simulation), which may present identically, is explanation enough. Some of the most influential figures in neurology and psychiatry over the past few centuries, including Sydenham, Briquet and, most importantly, Charcot, Janet and Freud, have wrestled with this condition and developed their own theories. Over the past century, a post-Freudian theory of conversion disorder has come to predominate within psychiatry at least, but this looks increasingly anomalous as psychodynamic theories are more widely abandoned in the search for neurobiological models or multifactorial aetiologies.

In this article we discuss the question of how conversion disorder is diagnosed. We look at the current criteria, the evidence for them and suggest how they might be improved. We deliberately do not tackle the issue of terminology which is so often laboured over, but use the term 'conversion disorder' as a term that is currently formalised and not because of any particular theoretical preference.

\section{The psychiatric history of 'conversion disorder'}

That it is still helpful, or even necessary, to review historical models of the disorder reflects our lack of progress in confirming or refuting these models. The puzzle of hysteria, as it was previously known, had been documented for millennia, ${ }^{4}$ but only began to assume its current form in the 19th century. Although physicians as far back as Willis had previously taken a psychological view of hysteria ${ }^{5}$ and others had considered it to be malingering, the debate crystallised with the development of post-mortem neuropathology whereby many other neurological disorders were found to have distinct anatomical and cellular abnormalities. ${ }^{6}$ The absence of pathology led Charcot to use the term 'functional' to describe conversion disorder and other 'nevroses', such as migraine, where no pathology was demonstrable but in which function was clearly disturbed, concluding that there must be a 'dynamic' lesion. This countered the view that its anomalous nature could best be explained by feigning, and so, as Freud later put it, restored 'dignity to the topic', although Charcot's particular model did not survive long after his death.

Psychological theories of conversion disorder were increasingly found in neurological thinking in the mid to late 19th century but it was not until the models of Freud $^{8}$ and Janet ${ }^{9}$ that they prevailed. ${ }^{5}$ Pierre Janet proposed that 'dissociation' could explain the symptoms as a defect in the psychological constitution. He suggested that dissociation could lead to problems maintaining the normal conscious synthesis of experiences: "a special moral weakness, consisting in the lack of 
power, on the part of the feeble subject, to gather, to condense his psychological phenomena, and assimilate them to his personality". "He proposed that under a variety of conditions, including trauma, a rogue 'idea', such as that of a weak limb, could become fixed, and separated from the consciousness that was too weak to exert control over it.

Freud proposed a different mechanism in which unwelcome experiences are 'repressed' into the unconscious, but in doing so become 'converted' into physical symptoms: "she repressed her erotic idea and transformed the amount of its affect into physical sensations of pain". 8 Freud argued that although the repression was deliberate, in order to escape from distress (which he called 'primary gain'), the conversion was not: "The splitting of the consciousness ...is accordingly a deliberate and intentional one ...the actual outcome is something different from what the subject intended". 'Secondary gains' could also accrue as the resulting physical symptoms enabled escape from conflicts or other unwanted outcomes-for example, paralysis stopping a partner leaving or resulting in more attention from a significant other. Freud later revised his view to argue that these traumas were only so debilitating because they awakened memories of childhood sexual abuse, and then dropped the latter idea in favour of his theory of infantile sexuality. Although he subsequently revised this view again, those early ideas of repression, conversion and sexual abuse came to dominate postFreudian psychiatric models of hysteria. 510

The acceptance of these models changed hysteria from a neurological condition akin to migraine into a purely psychiatric disorder. Over the 20th century psychiatrists embraced the condition even as they noted its apparent disappearance from their clinics ${ }^{11}$ (although its actual prevalence showed little evidence of decline). ${ }^{12}$ Hysteria entered the diagnostic classification, with terminology that embodied the dominant Freudian model-conversion hysteria. In the latter part of the century, as enthusiasm for biological psychiatry grew, in the UK in particular, there were moves to a more neutral model. Successive iterations of the diagnostic criteria became increasingly 'agnostic' in terms of a specific psychological model, ${ }^{13}$ and the term dissociation, still in common use in psychological circles, re-entered the nomenclature in ICD-10, describing 'dissociative seizures' and becoming a synonym in 'dissociative (conversion) disorder'.

\section{Current psychiatric criteria}

The psychiatric criteria in use today (DSM-IV ${ }^{14}$ and ICD-10) ${ }^{15}$ continue this trend, requiring psychiatrists to understand their conversion disorder patients' symptoms in psychosocial terms without stipulating a model for doing so. The only formal requirements are that there be associated psychological stressors and that whatever mechanism is hypothesised it cannot be deliberate feigning. Both systems define the condition similarly and share four key diagnostic requirements (see box 1).

Box 1 The four key diagnostic features of conversion disorder

1. Neurological symptoms involving motor or sensory symptoms or loss of consciousness

2. No evidence of organic (neurological) disease that can explain the symptoms

3. Associated psychological stressors (relevant to onset of symptoms)

4. Conscious simulation (feigning) is excluded
The current formal criteria therefore commit to a model that assumes conversion disorder is distinguishable from (organic) neurological disorders, a psychological explanation always being identifiable (and therefore that a positive psychological diagnosis can be made) and that it is different to and distinguishable from feigning. However, there are significant problems with these assumptions both in theory and in practice as we shall discuss. These issues reflect deep uncertainties at the core of our current understanding of the condition.

\section{IS CONVERSION DISORDER DISTINGUISHABLE FROM NEUROLOGICAL DISORDER?}

Although history, examination and investigation may exclude other neurological disorders, there are positive signs, both neurological and psychological, which neurologists employ to make the diagnosis of conversion disorder. ${ }^{1}{ }^{16}$ Positive neurological signs may be such typical features as a dragging gait in leg weakness, a clenched fist in 'psychogenic' dystonia or prolonged seizures with eyes shut in dissociative seizures. Alternatively, they may be signs of 'internal inconsistency'-for example, a highly distractible tremor or Hoover's sign (increased power of hip extension in the affected leg on contralateral hip flexion). ${ }^{17}$ Such signs, like all physical signs, have limitations. ${ }^{18} 19$ Their reliability is poorly studied in patients with motor and sensory symptoms ${ }^{20}$ although studies on semiology of dissociative seizures are somewhat better. The differentiation is particularly difficult when patients have conversion symptoms and an underlying neurological disease, ${ }^{21}$ a situation sometimes known as 'functional overlay'

Positive psychological features (in addition to the psychological formulation) have also been popular. 'La Belle indifference', a 'relative lack of concern about the nature or implication of the symptoms' ${ }^{14}$ is a psychological sign popularised by Freud, ${ }^{8}$ but there is little evidence for its specificity. It is commonly found in organic disease, may be a marker of feigning or just indicate a patient who is distressed but trying hard to "put on a brave face'. ${ }^{22}$ Histrionic or borderline personality disorders are more common in patients with conversion disorder than controls but still affect only a minority of patients. Other psychological features, such as the presence of a 'model' for the symptoms (eg, having seen a relative present similarly) have not been consistently confirmed by studies. In the case of secondary gain there is again inconsistent evidence although there is support for its role in somatisation. ${ }^{23}$ Regardless of the reliability of psychological features, it appears that neurologists generally ignore them in deciding whether a particular symptom is 'non-organic'. For example, of 519 neurologists recently surveyed about psychogenic movement disorders, only $18 \%$ reported needing evidence of an emotional disturbance to make the diagnosis. ${ }^{16}$

Whatever methods are used, conversion disorder does appear to have reasonable diagnostic stability. Slater's well known 1965 follow-up study of hysteria asserted that a significant proportion of patients with a diagnosis of 'hysteria' were later found to have had missed neurological diagnoses ${ }^{24}$ but since 1970 followup studies have found misdiagnosis rates similar to other neurological and psychiatric presentations (around $4 \%$ at 5 years). ${ }^{1}{ }^{25}$ It seems that the diagnostic reliability and stability comes from the exclusion of or incompatibility with neurological disease rather than from the psychiatric formulation. ${ }^{26}$

\section{The implications for conversion disorder}

Despite historical concerns, conversion disorder appears to be distinguishable from neurological disorder and this stems 
predominantly from the neurologist's assessment. However, the combination of concern about misdiagnosis, a lack of understanding by psychiatrists of the process of neurological diagnosis and the limited reliability of psychological features may explain why patients with conversion disorder are so often sent back from general psychiatrists with the opinion "no psychiatric disorder found, are you sure it's not organic?"16 While this may reflect diagnostic caution on the part of psychiatrists, or simply their failure to consider the possibility of conversion disorder, it could also reflect a more serious challenge to the assumption that psychological factors are either identifiable, or indeed relevant, to the onset and therefore the aetiology of this disorder, as we consider below.

\section{CAN A POSITIVE PSYCHOLOGICAL FORMULATION BE MADE?}

Making sense of a patient's problems in psychosocial terms requires a model, or models, for how psychosocial factors can come to have such physical effects. Although such models form the foundation of the psychiatric view of conversion disorder, the current criteria have stepped back from stipulating what that model should be, as we described above, and limited the diagnostic requirement to finding an associated psychological stressor. Determining what constitutes a psychological 'association', however, requires some idea of what an association looks like. Should this be temporal, as in a recent stressful live event, or historic, as in Freudian childhood sexual trauma, or symbolic, as the post-Freudians would hold? Are the kinds of stressor specific to the disease or to the person, or both? Are they triggers or risk factors?

Psychological stress is universal and is known to be associated with exacerbation or the precipitation of not only psychiatric illness, such as depression ${ }^{27}$ and schizophrenia, ${ }^{28}$ but also physical illnesses such as acute coronary syndromes ${ }^{29}$ or multiple sclerosis. ${ }^{30}$ But these associations do not prove causation. Furthermore, in clinical practice, potential psychological stressors are so common, especially if one extends back to childhood, that they may simply be coincidental at an individual patient level. It should also be noted that psychiatric disorder is as common in neurology patients as it is in other physical health disorders. For neurology inpatients, the prevalence of all psychiatric disorders has been estimated at $34 \%^{31}$ and in a sample of 300 outpatients the prevalence of depressive disorders was $40 \%{ }^{32}$

Studies systematically examining the relationship between stress and conversion disorder are disappointingly thin on the ground. What do they tell us about specific stressors associated with symptom onset? Is there any evidence to demonstrate a causal relationship?

\section{Are psychological stressors found at elevated rates before symptom onset?}

The evidence with regard to this key question is mixed. Studies which take the precipitating stress diagnostic criterion literally (such as Deveci ${ }^{33}$ ) will of course find stress preceding every case. Among those that were not as strict, a pair of studies assessing 50 conversion patients found a similar (approximately threefold) elevation of life events in the year, and particularly the 3 months, before symptom onset relative to neurology controls and this was more marked for patients with non-epileptic attacks compared with motor conversion disorder patients. ${ }^{34} 35$ Similarly, a study of globus pharyngis (persistent sensations of a lump in the throat with no identifiable physical cause) found increased rates of stressors in the year, and particularly the month, preceding symptom onset compared with disease controls. $^{36}$

However, other studies have failed to find significant differences compared with neurological ${ }^{18} 19$ and, importantly, psychiatric (mood disorder) ${ }^{37}$ controls. The ubiquity of stressors in non-psychiatric illness is highlighted by a study of 153 neurology inpatients which found legal, financial and family stresses in equal proportions (approximately 20\%) of both those with neurological and those with somatoform, including conversion, disorders. ${ }^{38}$ It is important to note that many studies in this area do not detail the methods used to identify psychological stressors, and relevant stressors may be missed if the assessments are not sufficiently sensitive.

\section{Are specific recent stressors associated with conversion disorder?}

Here again the evidence is mixed. Studies have identified multiple different stressors-for example, work and relationship problems ${ }^{37}{ }^{39}$-for which there is some evidence of correlation with symptom severity ${ }^{37}$ but no single key stressor type has emerged. However, when specific presentations are studied there is some evidence for the role of more specific stressors such as those that fit a psychological 'model'. For example, 54\% of patients with functional dysphonia, but only $16 \%$ of controls, were found to have an identifiable stressor that, rated blindly to controls, carried significant 'conflict over speaking out' — such as the patient being unable to disclose to friends and family that they were being physically abused by their husband. ${ }^{40}$ This provides a seductive link between the nature of the stressor and the resulting symptoms but such compelling connections have not been found elsewhere.

\section{Are historical stressors associated with conversion disorder?}

An association with childhood abuse, particularly sexual abuse, has been implicated since at least Freud's early writing. ${ }^{41}$ However, it should be noted that childhood abuse is a risk factor for many, indeed most, psychiatric disorders. ${ }^{42}$ In particular, personality disorders are associated with sexual abuse and dissociative symptoms ${ }^{43}$ and are present at higher rates in patients with conversion disorder than neurological controls and could represent an important confounder. Accurately assessing the incidence of abuse in patients or the general population is also notoriously hard due to difficulties in defining abuse, the pressures for or against disclosure and difficulties in recall of memories that may be repressed.

Reviews of childhood abuse in conversion disorder, predominantly in non-epileptic seizure patients, have identified a total of 26 controlled studies. ${ }^{44-46}$ One review pooled the effect sizes of 717 patients and 152 controls to give an odds ratio of 2.9 for sexual abuse. ${ }^{46}$ Studies published since the searches of these reviews have been consistent with these findings. ${ }^{47} 48$ In one large general population study, previous sexual abuse predicted conversion disorder, mediated by a comorbid lifetime diagnosis of depression or (other) dissociative disorders. ${ }^{47}$ Several other studies have identified mediating factors for sexual abuse, including hypnotic susceptibility, adult life events, family dysfunction, somatisation and tendency to dissociation. ${ }^{44}$ However, not all conversion disorder patients are found to have a history of childhood physical or sexual abuse with absolute rates in these three reviews varying widely (0-85\%) with the mean in non-epileptic seizure patients estimated at approximately $30 \%$ for both forms of abuse. ${ }^{46}$ So it appears that childhood abuse can only be a partial explanation of the problem. Perhaps sexual abuse could create a vulnerability to 
later trauma, as has been demonstrated in post-traumatic stress disorder. $^{49}$

\section{Is there evidence for a mechanistic link between psychological stressors and conversion symptoms?}

If the psychological model is accepted how do psychological stressors lead, or 'convert', to neurological symptoms? A few studies have started to address how such 'conversion' may occur, and whether this fits with the Freudian model of repression.

The neural correlates of remembering the stressor presumed to be of key aetiological significance has been investigated in a functional MRI study of a single case of motor conversion disorder. Compared with remembering an equally severe event (of no theoretical aetiological significance), differential activations provided preliminary evidence for a potential conversion mechanism whereby frontal cortical structures inhibit the motor pathway. ${ }^{50}$ This study also found preliminary evidence for repression in that there was relative activation of the amygdala despite subjective reports of little emotional stress.

A study of non-epileptic seizure patients found attentional bias for emotional stimuli (angry faces) compared with healthy controls and this was associated with previous sexual abuse ${ }^{51}$ and baseline cortisol levels. ${ }^{52}$ This can be interpreted as providing, again preliminary, evidence for a state of emotional 'hypervigilance' that results from sexual abuse and is aetiologically important in conversion, perhaps creating a disposition to dissociation.

A different approach is to examine the events and symptoms just prior to symptom onset to see if they can inform a model of conversion disorder and why certain symptoms might occur. Panic symptoms have been found to occur commonly as prodromal symptoms of dissociative seizures, and two thirds of 25 patients experienced shortness of breath, racing heartbeat and tingling as part of their attack when questioned closely. ${ }^{53}$ Similarly, physical injury has a long historical association with conversion disorder. A recent systematic review of 133 studies and 869 patients with motor and sensory conversion symptoms found that $37 \%$ reported a physical injury prior to symptom onset. ${ }^{54}$ The amplification of a normal immobility response to threat could be seen as a tangible mechanism whereby the physiological and psychological consequences of life events might lead to conversion symptoms. ${ }^{55}$ It has also been proposed that physical injuries, including relatively minor ones, could also stimulate a similar 'primitive protection or avoidance mechanism' ${ }^{56}$

\section{The implications for conversion disorder}

Finding a psychological explanation does not seem to be universally possible in conversion disorder. As with the feigning exclusion, a rigid interpretation would leave many patients that clinicians consider to have the condition without a formal diagnosis. Even when such an explanation can be found there is some evidence that this is not reliable in the sense of having high inter-rater reliability. ${ }^{57}$ When an explanation is reduced to the presence of a stressor, its importance is uncertain due to the considerable problems of establishing causality from a relatively common factor that is also associated with many other psychiatric, and some physical, disorders. However, there is some relatively consistent evidence that previous childhood abuse, particularly sexual abuse, is associated with conversion disorder and could play an aetiological role, possibly by predisposing to dissociative phenomena. Efforts are underway to establish a link between such stressors and the symptoms of conversion and therefore probe the possible mechanisms of the disorder but no firm conclusions can yet be drawn. Therefore, the presence of a psychological formulation does not seem to be a practical diagnostic criterion-at least not a formal requirement, as is currently the case.

\section{IS CONVERSION DISORDER DIFFERENT TO FEIGNING?}

Medical feigning is the deliberate simulation of symptoms. It is conventionally divided into factitious disorder and malingering according to the nature of the motivation behind it. In factitious disorder the motivation is to receive medical care and in malingering it is something 'external', commonly a financial reward (eg, an insurance claim). Both are defined as completely distinct from conversion disorder-factitious disorder is still considered a psychiatric disorder as the motives are psychological but malingering is regarded simply as adaptive criminal behaviour. How is the distinction between feigning and conversion disorder justified?

How does feigning differ theoretically from conversion disorder? The current orthodoxy presumes conversion disorder is distinct from feigning in that symptoms are not under conscious control. This neat distinction between malingering, factitious disorder and conversion disorder is relatively new. ${ }^{58}$ For much of the last century psychiatrists and neurologists debated whether and where such a line could be drawn since, for many, factitious disorder was a clear sign of psychopathology, and hysteria had such clear secondary gains. This debate was sharply focused by the issues of shell shock and compensation neurosis, as many thousands of men developed 'non-organic' neurological symptoms in situations of clear gain (eg, getting away from combat or getting money for being off work). The decision in favour of the current system was political as much as medical, ${ }^{59} 60$ and only gradually resolved in favour of the current divide. Yet many today would consider there to be a spectrum of awareness or conscious control, both between individuals and within an individual over time, rather than a clear division. ${ }^{58}$ Feigning is still often suspected by neurologists, ${ }^{61}$ sometimes by the relatives and friends of patients and occasionally even by the patients themselves. This only reinforces the question as to why so many people, then and now, see feigning as an explanation for conversion disorder.

The most obvious reason is that conversion disorder looks like feigning - that is, the clinical features are similar, if not identical. ${ }^{62} 63$ Inconsistent symptoms, particularly weakness or tremor that improves when distracted, are hallmarks of both conditions and, in the case of these symptoms, probably reflect both conditions being a product of the voluntary motor system. Deception, in all forms, is also widespread in human, and indeed other animal, behaviour. But is it true that the two are clinically indistinguishable and what implications does this have for diagnostic criteria?

\section{Can feigning be distinguished from conversion disorder?}

If feigning and conversion disorder look identical then distinguishing the two will fall to our ability to interpret conscious motivation-or, put more simply, to detect lying. Unfortunately, there is a substantial body of evidence now showing that liars have the upper hand over human lie detectors. Age, experience and professional training seem to have no significant impact on our general inability to spot lies. ${ }^{64}$ Our behavioural methods have long been supplemented with a variety of other techniques, however. Charcot used tremor recordings in attempts to differentiate hysterical catalepsy (sustained limb posturing) from malingering ${ }^{65}$ and since then an increasingly 
wide range of approaches have been applied to differentiating conversion disorder from feigning, with limited success. It should be noted that these studies are limited by the assumptions that the conversion disorder patients studied are not actually misdiagnosed feigners and, conversely, those studying 'real' feigners (rather than controls instructed to feign) are not conversion disorder cases.

\section{Neurological features}

There are no bedside tests that can be interpreted as showing unambiguously deliberate intent to deceive in a patient with neurological symptoms. Whereas in other specialities tampering with laboratory tests or a ligature mark can be discovered, in neurology the only definitive methods for differentiating between feigned and conversion disorder symptoms are a direct confession from the patient or covert surveillance demonstrating behaviour that could not possibly be unconscious or the result of having a 'good day'-for example, a 'paralysed' patient in a wheelchair caught playing football. ${ }^{66}$

\section{Psychiatric features}

A number of clinical features may point towards a patient who is exaggerating or feigning. ${ }^{67}$ While the hallmark of conversion disorder may be inconsistency in physical signs there should not be increased levels of inconsistency in the history relative to other conditions. Therefore, major inconsistencies within the history, between the patient and an informant or the medical records or between different consultations over time are red flags for feigning.

\section{Neuropsychology tests}

'Effort tests' attempt to detect either a lack of effort to pass, or even an active effort to fail, cognitive tasks and are widely use to validate cognitive testing as a true representation of ability, and are therefore also widely known as 'symptom validity tests'. ${ }^{6}$ The simplest example is the 'coin in the hand' test ${ }^{69}$ where a coin is shown in one hand and, after a brief distraction task (counting backwards from 10), later asked which hand it is in. Organic amnestic patients perform this task surprisingly well but malingering patients score at chance (ie, 50\%). Intriguingly, base rates of failure on such tasks are higher in compensation seeking individuals with other presenting complaints such as fibromyalgia and chronic pain ${ }^{68}$ and as a result these tests have been used as a general indicator of somatoform disorders.

Some recent evidence that conversion disorder may be different to feigning comes from a study which found that only $11 \%$ of 43 conversion disorder patients failed effort testing, compared with $94 \%$ of controls instructed to be subtle simulators, and $100 \%$ of controls instructed to be blatant simulators. ${ }^{70}$ Five other studies have used effort tests to compare conversion disorder (mostly non-epileptic seizure patients) to organic controls (mostly epilepsy patients) with mixed results. One found a fivefold increase in failure rates, ${ }^{71}$ one found a twofold increase ${ }^{72}$ but three found no increase. ${ }^{73-75}$ None of these other studies examined control malingerers. Effort tests are appealing in their design but can be problematic in interpretation. Most significantly, they cannot determine whether someone is consciously or unconsciously choosing to fail the test. They also do not give any direct evidence on whether an associated physical symptom is feigned.

There have been attempts to use symptom validity tests directly in relation to conversion disorder with specific sensory deficits. There is some evidence from case reports in deafness ${ }^{76}$ and blindness ${ }^{77} 78$ for conversion patients performing differently to feigners. However, there are some contradictory case reports in blindness. ${ }^{79-81}$

\section{Neurophysiology}

Case studies examining possible differences in P300 evoked potentials in patients with conversion sensory loss ${ }^{82}$ and visual symptoms ${ }^{83}$ compared with people feigning the same symptoms are intriguing but have also yielded inconsistent results.

\section{Neuroimaging}

A study of two patients with conversion disorder showed different activations on attempting to move their weak arm compared with two controls simulating the same weakness and six controls moving normally. ${ }^{84}$ Eight patients with conversion disorder tremor had different activations during activation of their tremor compared with controls simulating tremors. ${ }^{85}$ Different activations were also found in four patients moving their weak ankle compared with their normal ankle and four controls simulating similar weakness or moving their ankle normally, ${ }^{86}$ with conversion disorder patients showing a distinct and more complex pattern of mental activity than feigners.

Another study used hypnotically induced weakness in controls as a model for conversion disorder and showed that the neural correlates during attempted movement were distinct from feigned weakness ${ }^{87}$ but similar to those of conversion disorder. $^{89}$ Similarly a 'go-nogo' task in hypnotically induced weakness showed distinct correlates from feigned weakness ${ }^{90}$ but similar to those of conversion disorder. ${ }^{91}$ These studies are considered in more detail in Bell et al. ${ }^{92}$

\section{The implications for conversion disorder}

The conclusion of the above must be that it remains extremely difficult to prove that someone with neurological symptoms is feigning, rather than suffering from a conversion disorder, on clinical or even experimental grounds. It is perhaps even more difficult to prove they are not feigning. If the current criteria were to be strictly interpreted, therefore, making a diagnosis of conversion disorder would not usually be possible.

There are more general reasons against feigning as a dominant explanation for conversion disorder of course. Conversion disorder is highly comorbid with other somatoform disorders; patients are typically bewildered by their symptoms and are generally keen for investigations. Feigning also appears less plausible as an explanation of long term follow-up studies of conversion disorder showing persistence of symptoms. Ultimately, we do not know how common feigning in neurology is, for the reasons given above. We know it does rarely occur, ${ }^{93}$ that it can occur in cases that were previously diagnosed as conversion disorder (commonly as a result of surveillance evidence being produced in court) and it is inevitable that some-possibly most-cases go undetected, or unreported. ${ }^{66}$ Feigning, therefore, is a possible explanation for conversion disorder, and one that undoubtedly explains a small minority of cases, but it is not a distinction that appears to have clinical utility.

\section{CONCLUSIONS}

Conversion disorder remains a problematic diagnosis. Its nature and mechanism remain largely unknown and we find ourselves having made disappointingly little progress in the last 100 years or so. Although we may be less concerned that we are missing a neurological disease in diagnosing conversion disorder, we continue to understand and define it by criteria that are not themselves clearly understood and whose presence we cannot clearly define. 
Although neurophysiological, neuropsychological and functional imaging studies may yet bear fruit there is currently no reliable or practical way of distinguishing conversion disorder from feigning at the bedside. The diagnostic criterion for the presence of a psychological explanation of the symptoms is equally problematic as psychological stressors are not always identifiable and may not be relevant even when present.

Both DSM and ICD diagnostic systems are currently under review. We propose that both the criteria for 'not feigning' and 'psychological stressors' should be dropped from formal criteria but retained in the background description of the disorder. We would also support incorporating reference to the methods actually used to make the physical diagnosis of conversion disorder within psychiatric diagnostic criteria and therefore the creation of a 'positive' neurological criteria as well as the 'negative' criteria of excluding organic disease.

For all the continued importance of a psychological formulation to therapeutics, clinicians should not be required to make decisions on criteria that are not decidable and, with others, we have expounded this principle and the above recommendations for changes to the diagnostic criteria. ${ }^{94} 95$ When a patient's symptoms are classified as psychiatric but largely diagnosed by neurologists, there is a need for mutual understanding of both neurological and psychological aspects by all clinicians managing such patients.

Funding RAAK was supported by the Wellcome Trust; TRJN was supported by the Medical Research Council.

Competing interests None.

Contributors All authors participated in the conception and writing of this paper.

Provenance and peer review Commissioned; externally peer reviewed.

\section{REFERENCES}

1. Stone J, Carson A, Duncan R, et al. Symptoms 'unexplained by organic disease' in 1144 new neurology out-patients: how often does the diagnosis change at followup? Brain 2009;132:2878-88

2. Stone J, Sharpe M, Rothwell PM, et al. The 12 year prognosis of unilateral functional weakness and sensory disturbance. J Neurol Neurosurg Psychiatry 2003;74:591-6.

3. Reuber M, Pukrop R, Bauer J, et al. Outcome in psychogenic nonepileptic seizures: 1 to 10-year follow-up in 164 patients. Ann Neurol 2003:53:305-11.

4. Veith I. Hysteria: the history of a disease. Northvale, NJ: Jason Aronson, 1993.

5. Mace CJ. Hysterical conversion I: A history. Br J Psychiatry 1992;161:369-77.

6. Shorter E. From paralysis to fatigue: a history of psychosomatic illness in the modern era. New York: Free Press, 1992.

7. Freud SC. In: Freud S, Strachey J, Freud A, et al, eds. The standard edition of the complete psychological works of Sigmund Freud. London: Hogarth Press, 1953.

8. Breuer J, Freud S. Studies in Hysteria. Franz Deuticke, Liepzig and Vienna 1895.

9. Janet PMFI. The major symptoms of hysteria: fifteen lectures given in the Medical School of Harvard University. New York: Macmillan, 1907.

10. Gottlieb RM. Psychosomatic medicine: the divergent legacies of Freud and Janet. J Am Psychoanal Assoc 2003:51:857-81.

11. Micale MS. On the "disappearance" of hysteria. a study in the clinical deconstruction of a diagnosis. Isis 1993;84:496-526.

12. Stone J, Hewett $\mathrm{R}$, Carson A, et al. The 'disappearance' of hysteria: historical mystery or illusion? J $R$ Soc Med 2008;101:12-8.

13. Martin RL. Diagnostic issues for conversion disorder. Hosp Community Psychiatry 1992:43:771-3.

14. APA. Diagnostic and statistical manual of mental disorder, 4th edn. Washington, DC: American Psychiatric Association, 1994

15. WHO. The ICD-10 classification of mental and behavioural disorders. Geneva: World Health Organisation, 1992

16. Espay AJ, Goldenhar LM, Voon V, et al. Opinions and clinical practices related to diagnosing and managing patients with psychogenic movement disorders: an international survey of movement disorder society members. Mov Disord 2009:24:1366-74.

17. Stone J. The bare essentials: Functional symptoms in neurology. Pract Neurol 2009:9:179-89.

18. Gould R, Miller BL, Goldberg MA, et al. The validity of hysterical signs and symptoms. J Nerv Ment Dis 1986;174:593-7.

19. Chabrol H, Peresson G, Clanet M. Lack of specificity of the traditional criteria for conversion disorders. Eur Psychiatry 1995;10:317-19.
20. Ziv I, Djaldetti R, Zoldan Y, et al. Diagnosis of "non-organic" limb paresis by a novel objective motor assessment: the quantitative Hoover's test. J Neurol 1998;245:797-802.

21. Eames P. Hysteria following brain injury. J Neurol Neurosurg Psychiatry 1992; 55:1046-53.

22. Stone J, Smyth R, Carson A, et al. La belle indifference in conversion symptoms and hysteria: systematic review. Br J Psychiatry 2006;188:204-9.

23. Craig TK, Drake H, Mills K, et al. The South London Somatisation Study. II. Influence of stressful life events, and secondary gain. Br J Psychiatry 1994;165:248-58.

24. Slater ET, Glithero E. A follow-up of patients diagnosed as suffering from "hysteria". J Psychosom Res 1965:9:9-13.

25. Stone J, Smyth R, Carson A, et al. Systematic review of misdiagnosis of conversion symptoms and "hysteria". BMJ 2005;331:989.

26. Moene FC, Landberg EH, Hoogduin KA, et al. Organic syndromes diagnosed as conversion disorder: identification and frequency in a study of 85 patients. J Psychosom Res 2000;49:7-12.

27. Brown GW, Bifulco A, Harris TO. Life events, vulnerability and onset of depression: some refinements. Br J Psychiatry 1987;150:30-42.

28. van $\mathbf{O s} \mathbf{J}$, Fahy $T A$, Bebbington $P$, et al. The influence of life events on the subsequent course of psychotic illness. A prospective follow-up of the Camberwell Collaborative Psychosis Study. Psychol Med 1994;24:503-13.

29. Dimsdale JE. Psychological stress and cardiovascular disease. J Am Coll Cardiol 2008:51:1237-46.

30. Mohr DC, Hart SL, Julian L, et al. Association between stressful life events and exacerbation in multiple sclerosis: a meta-analysis. BMJ 2004;328:731.

31. Fink P, Hansen MS, Sondergaard L, et al. Mental Illness in new neurological patients. J Neurol Neurosurg Psychiatry 2003;74:817-19

32. Carson AJ, Postma K, Stone J, et al. The outcome of depressive disorders in neurology patients: a prospective cohort study. J Neurol Neurosurg Psychiatry 2003;74:893-6.

33. Deveci A, Taskin 0, Dinc G, et al. Prevalence of pseudoneurologic conversion disorder in an urban community in Manisa, Turkey. Soc Psychiatry Psychiatr Epidemio 2007:42:857-64

34. Binzer M, Andersen PM, Kullgren G. Clinical characteristics of patients with moto disability due to conversion disorder: a prospective control group study. J Neurol Neurosurg Psychiatry 1997;63:83-8.

35. Stone J, Sharpe M, Binzer M. Motor conversion symptoms and pseudoseizures: a comparison of clinical characteristics. Psychosomatics 2004;45:492-9.

36. Harris MB, Deary IJ, Wilson JA. Life events and difficulties in relation to the onset of globus pharyngis. J Psychosom Res 1996;40:603-15.

37. Roelofs K, Spinhoven P, Sandijck P, et al. The impact of early trauma and recent lifeevents on symptom severity in patients with conversion disorder. J Nerv Ment Dis 2005; 193:508-14.

38. Creed F, Firth D, Timol M, et al. Somatization and illness behaviour in a neurology ward. J Psychosom Res 1990:34:427-37.

39. Deka K, Chaudhury PK, Bora K, et al. A study of clinical correlates and socio demographic profile in conversion disorder. Indian J Psychiatry 2007:49:205-7.

40. House A0, Andrews HB. Life events and difficulties preceding the onset of functional dysphonia. J Psychosom Res 1988;32:311-19.

41. Freud S. Further remarks on the neuro-psychoses of defence. In: Strachey J, et al eds. The standard edition of the complete psychological works of Sigmund Freud. London: Hogarth Press 1953;3:162-85.

42. Johnson CF. Child sexual abuse. Lancet 2004:364:462-70.

43. Ball JS, Links PS. Borderline personality disorder and childhood trauma: evidence for a causal relationship. Curr Psychiatry Rep 2009;11:63-8.

44. Roelofs K, Spinhoven P. Trauma and medically unexplained symptoms towards an integration of cognitive and neuro-biological accounts. Clin Psychol Rev 2007:27:798-820.

45. Fiszman A, Alves-Leon SV, Nunes RG, et al. Traumatic events and posttraumatic stress disorder in patients with psychogenic nonepileptic seizures: a critical review. Epilepsy Behav 2004:5:818-25.

46. Sharpe D, Faye C. Non-epileptic seizures and child sexual abuse: a critical review of the literature. Clin Psychol Rev 2006:26:1020-40.

47. Sar V, Akyuz G, Kundakci T, et al. Childhood trauma, dissociation, and psychiatric comorbidity in patients with conversion disorder. Am J Psychiatry 2004:161:2271-76.

48. Sar V, Akyuz G, Dogan 0, et al. The prevalence of conversion symptoms in women from a general Turkish population. Psychosomatics 2009:50:50-8.

49. Xie P, Kranzler HR, Pooling J, et al. Interactive effect of stressful life events and the serotonin transporter 5-HTTLPR genotype on posttraumatic stress disorder diagnosis in 2 independent populations. Arch Gen Psychiatry 2009;66:1201-9.

50. Kanaan RA, Craig TK, Wessely SC, et al. Imaging repressed memories in motor conversion disorder. Psychosom Med 2007;69:202-5.

51. Bakvis P, Roelofs K, Kuyk J, et al. Trauma, stress, and preconscious threat processing in patients with psychogenic nonepileptic seizures. Epilepsia 2009:50:1001-11.

52. Bakvis $\mathbf{P}$, Spinhoven P, Roelofs K. Basal cortisol is positively correlated to threat vigilance in patients with psychogenic nonepileptic seizures. Epilepsy Behav 2009:16:558-60

53. Goldstein LH, Mellers JD. Ictal symptoms of anxiety, avoidance behaviour, and dissociation in patients with dissociative seizures. J Neurol Neurosurg Psychiatry 2006:77:616-21. 
54. Stone J, Carson A, Aditya $\mathrm{H}$, et al. The role of physical injury in motor and sensory conversion symptoms: a systematic and narrative review. J Psychosom Res 2009;66:383-90.

55. Kretschmer E. Hysteria: reflex and instinct. London: Peter Owen, 1948.

56. Vuilleumier P. Hysterical conversion and brain function. Prog Brain Res 2005:150:309-29.

57. Schneider W, Freyberger HJ, Muhs A, et al. Results of the ICD-10 research criteria study in German-speaking countries in the field of psychosomatics and psychotherapy. Psychopathology 1996;29:306-14.

58. Kanaan RA, Wessely S. The origins of factitious disorder. Hist Hum Sci 2010;23:68-85.

59. Wessely S. Malingering: Historical perspectives. In: Halligan PW, Bass CM, Oakley DA, eds. Malingering and illness deception. New York: Oxford University Press, 2003:31-41.

60. Cooter R. Malingering in modernity: psychological scripts and adversial encounters during the First World War. In: Cooter R, Harrison M, Sturdy S, eds. War, medicine and modernity. Stroud: Sutton 1998:125-48.

61. Kanaan R, Armstrong D, Barnes P, et al. In the psychiatrist's chair: how neurologists understand conversion disorder. Brain 2009;132:2889-96.

62. Spence SA. Hysterical paralyses as disorders of action. Cogn Neuropsychiatry 1999;4:203-26

63. Miller E. Conversion hysteria: is it a viable concept? Cogn Neuropsychiatry 1999:4:181-91.

64. Aamodt MG, Custer $\mathrm{H}$. Who can best catch a liar? a meta-analysis of individual differences in detecting deception. Forensic Examiner 2006:6-11.

65. Goetz CG. J.-M. Charcot and simulated neurologic disease: attitudes and diagnostic strategies. Neurology 2007:69:103-9.

66. Kanaan R, Wessely S. Factitious disorders in neurology: an analysis of reported cases. Psychosomatics 2010;51:47-54.

67. Sharpe M. Distinguishing malingering from psychiatric disorders. In: Halligan PW, Bass C, Oakley DA, eds. Malingering and illness deception. Oxford: Oxford University Press, 2003:156-70.

68. Heilbronner RL, Sweet JJ, Morgan JE, et al. American Academy of Clinical Neuropsychology Consensus Conference Statement on the neuropsychological assessment of effort, response bias, and malingering. Clin Neuropsychol 2009;23:1093-129.

69. Kapur N. The coin-in-the-hand test: a new "bed-side" test for the detection of malingering in patients with suspected memory disorder. J Neurol Neurosurg Psychiatry 1994:57:385-6.

70. Kemp S, Coughlan AK, Rowbottom C, et al. The base rate of effort test failure in patients with medically unexplained symptoms. J Psychosom Res 2008;65:319-25.

71. Drane DL, Williamson DJ, Stroup ES, et al. Cognitive impairment is not equal in patients with epileptic and psychogenic nonepileptic seizures. Epilepsia 2006:47:1879-86.

72. Hill SK, Ryan LM, Kennedy $\mathrm{CH}$, et al. The relationship between measures of declarative memory and the test of memory malingering in patients with and without temporal lobe dysfunction. J Forensic Neuropsychol 2003;3:1-18.

73. Cragar DE, Berry DT, Fakhoury TA, et al. Performance of patients with epilepsy or psychogenic non-epileptic seizures on four measures of effort. Clin Neuropsychol 2006;20:552-66.
74. Dodrill CB. Do patients with psychogenic nonepileptic seizures produce trustworthy findings on neuropsychological tests? Epilepsia 2008;49:691-5.

75. van Beilen M, Griffioen BT, Gross A, et al. Psychological assessment of malingering in psychogenic neurological disorders and non-psychogenic neurological disorders: relationship to psychopathology levels. Eur J Neurol 2009;16:1118-23.

76. Pankratz L, Fausti A, Peed S. A forced-choice technique to evaluate deafness in the hysterical or malingering patient. J Consult Clin Psychol 1975;43:421-2.

77. Bryant RA, McConkey KM. Visual conversion disorder: a case analysis of the influence of visual information. J Abnorm Psychol 1989:98:326-9.

78. Grosz HJ, Zimmerman JA. A second detailed case study of functional blindness: further demonstration of the contribution of objective psychological laboratory data. Behav Ther 1970;1:115-23.

79. Grosz HJ, Zimmerman J. Experimental analysis of hysterical blindness: a follow-up report and new experimental data. Arch Gen Psychiatry 1965;13:255-60.

80. Theodor LH, Mandelcorn MS. Hysterical blindness: a case report and study using a modern psychophysical technique. J Abnorm Psychol 1973;82:552-3.

81. Miller $\mathbf{E}$. A note on the visual performance of a subject with unilateral functional blindness. Behav Res Ther 1968;6:115-16.

82. Lorenz J, Kunze K, Bromm B. Differentiation of conversive sensory loss and malingering by P300 in a modified oddball task. Neuroreport 1998:9:187-91.

83. Towle VL, Sutcliffe E, Sokol S. Diagnosing functional visual deficits with the P300 component of the visual evoked potential. Arch Ophthalmol 1985;103:47-50.

84. Spence SA, Crimlisk HL, Cope H, et al. Discrete neurophysiological correlates in prefrontal cortex during hysterical and feigned disorder of movement. Lancet 2000;355:1243-4.

85. Voon V, Gallea C, Hattori N, et al. The involuntary nature of conversion disorder. 2010;74:223-8.

86. Stone J, Zeman A Simonotto $\mathrm{E}$, et al. FMRI in patients with motor conversion symptoms and controls with simulated weakness. Psychosom Med 2007;69:961-9

87. Ward NS, Oakley DA, Frackowiak RS, et al. Differential brain activations during intentionally simulated and subjectively experienced paralysis. Cogn Neuropsychiatry 2003; 8:295-312

88. Halligan PW, Athwal BS, Oakley DA, et al. Imaging hypnotic paralysis: implications for conversion hysteria. Lancet 2000;355:986-7.

89. Marshall JC, Halligan PW, Fink GR, et al. The functional anatomy of a hysterical paralysis. Cognition 1997:64:B1-8.

90. Cojan Y, Waber L, Schwartz S, et al. The brain under self-control: modulation of inhibitory and monitoring cortical networks during hypnotic paralysis. Neuron 2009;62:862-75.

91. Cojan Y, Waber L, Carruzzo A, et al. Motor inhibition in hysterical conversion paralysis. Neuroimage 2009;47:1026-37.

92. Bell, Oakley DA, Halligan PW, et al. Dissociation in hysteria and hypnosis: evidence from cognitive neuroscience. J Neurol Neurosurg Psychiatry. Published Online First 30 September 2010. doi:10.1136/jnnp.2009.199158.

93. Bauer M, Boegner F. Neurological syndromes in factitious disorder. J Nerv Ment Dis 1996;184:281-8

94. Kanaan RA, Carson A, Wessely SC, et al. What's so special about conversion disorder? A problem and a proposal for diagnostic classification. Br J Psychiatry 196:427-8.

95. Stone J, LaFrance WC, Levenson JL, et al. Issues for DSM V: conversion disorder. Am J Psych 2010;167:626-7. 